\title{
Experimental study on the neurotoxic effect of $\beta$-amyloid on the cytoskeleton of PC12 cells
}

\author{
LAI WANG $^{1 *}$, JINGJING CAO $^{1 *}$, ZHENYU SHI $^{1}$, WENJUAN FAN $^{1}$, HONGLIANG LIU ${ }^{1}$, \\ JINBO DENG ${ }^{1}$ and JIEXIN DENG ${ }^{2}$ \\ ${ }^{1}$ Institute of Neurobiology, College of Life Sciences, Henan University; ${ }^{2}$ College of Nursing, \\ Henan University, Kaifeng, Henan 475004, P.R. China
}

Received July 5, 2016; Accepted January 31, 2018

DOI: $10.3892 / \mathrm{ijmm} .2018 .3467$

\begin{abstract}
The aim of the present study was to establish a cell model of Alzheimer's disease (AD) and investigate the neurotoxic effects of $\beta$-amyloid $(\mathrm{A} \beta)$ on the cytoskeleton. PC12 cells were cultured and treated with $\mathrm{A} \beta_{25-35}$, and cell survival was analyzed with the MTT assay. Cell apoptosis was visualized using 4',6-diamidino-2-phenylindole staining and the terminal deoxynucleotidyl transferase dUTP nick-end labeling assay. Immunocytochemistry and phalloidin staining were used to label the cytoskeleton of PC12 cells. A $\beta_{25-35}$ was found to induce PC12 cell apoptosis in a dose-dependent manner $(\mathrm{P}<0.05)$. Moreover, $\mathrm{A} \beta_{25-35}$ also caused dose-dependent disintegration of the cytoskeleton $(\mathrm{P}<0.05)$. Therefore, the PC12 cell cytoskeleton was found to be sensitive to $A \beta_{25-35}$ neurotoxicity. The disintegration of the cytoskeleton is likely an important pathological alteration in $\mathrm{AD}$, and $\mathrm{A} \beta$ is a key molecule involved in AD pathogenesis.
\end{abstract}

\section{Introduction}

Alzheimer's disease (AD) is a neurodegenerative disorder, and its pathological lesions often appear in the neocortex and, particularly, the hippocampus. An estimated 36 million individuals suffer from AD worldwide. In the UK, AD-related mortality is ranked no. 6 in the population aged $>65$ years, while in the United States it is ranked no. 5 (1). In China, the total number of $\mathrm{AD}$ patients is $>5$ million (2). Therefore, the prevention and treatment of AD represent major challenges for scientists and

Correspondence to: Dr Jinbo Deng, Institute of Neurobiology, College of Life Sciences, Henan University, 1 Jinming Road, Kaifeng, Henan 475004, P.R. China

Email: jinbo_deng@henu.edu.cn

Dr Jiexin Deng, College of Nursing, Henan University, 1 Jinming Road, Kaifeng, Henan 475004, P.R. China

E-mail: dengjiexin@yahoo.com

${ }^{*}$ Contributed equally

Key words: Alzheimer's disease, $\beta$-amyloid, cytoskeleton, neuroapoptosis, $\mathrm{PC} 12$ cells clinicians. The mechanism of AD pathogenesis has not yet been fully elucidated. There are numerous hypotheses, but the most widely accepted hypothesis is the amyloid cascade reaction. This hypothesis suggests that neurotoxic $\beta$-amyloid $(\mathrm{A} \beta)$ protein is deposited in the brain and triggers a series of pathological alterations, including amyloid plaques and neurofibrillary tangles (3). Previous studies confirmed that $\mathrm{A} \beta$ neurotoxicity causes formation of amyloid plaques in the neocortex through a variety of mechanisms (4); however, the asociation between the formation of neurofibrillary tangles and cytoskeletal alterations is not well understood. The cytoskeleton is a fibrous network mainly composed of microtubules, microfilaments and intermediate filaments. Previous studies demonstrated that, during cell apoptosis, the cytoskeleton exhibits major changes (5); therefore, the structure and function of the neuronal cytoskeleton may play an important role in the pathogenesis of neurodegenerative diseases (6). In the present study, the neurotoxic effect of $A \beta_{25-35}$ on the cytoskeleton were investigated in a PC12 cell culture, aiming to elucidate the role of the cytoskeleton in the pathogenesis of AD to provide novel insight and treatment strategies.

\section{Materials and methods}

PC12 cell culture. The PC12 adrenal pheochromocytoma cell line was purchased from the Institute of Cell Biology, Chinese Academy of Sciences (Shanghai, China). The present study used differentiated PC12 cells, as they share several characteristics with nervous cells and are widely accepted as a neuronal model. In addition, compared with primary neurons, the procedures of cell culturing are simple, with efficient cell proliferation. For the cell culture, PC12 cells removed from liquid nitrogen were thawed at $37^{\circ} \mathrm{C}$, and were then seeded and cultured in high-glucose Dulbecco's modified Eagle's medium (DMEM; 12100-038) with $10 \%$ fetal calf serum (FCS; 140714) (both from Gibco; Thermo Fisher Scientific, Grand Island, NY, USA) and $1 \%$ penicillin and streptomycin. PC12 cells in the adherent culture started to grow and differentiate and, after $24 \mathrm{~h}$, spindle-like and polygon-like cells were observed, with clear boundaries and a neuron-like shape. When cultured PC12 cells reached a confluence of $70-80 \%$, cell passaging was performed. Following digestion with $0.25 \%$ trypsin, the cells were collected and seeded for the following experiments. Some cells were cryopreserved in liquid nitrogen. 
$A \beta_{25-35}$ protein treatment and experimental grouping. $\mathrm{A} \beta$ accumulation in brain is the main event in the pathogenesis of AD; therefore, instead of toxic oligomers of the conventional 1-40 or 1-42 subtypes, $A \beta$ has been used as a inducer for the AD cell model (7). Naturally occurring $A \beta$ protein exhibits only weak neurotoxicity in vivo or in vitro; however, the aggregated $\mathrm{A} \beta$ protein and its fragments may be severely neurotoxic. This process is referred to as 'aging'. According to Pike et al (8), aged $\mathrm{A} \beta_{25-35}$ (A4559; Sigma-Aldrich; Merck, KGaA, St. Louis, MO, USA) was prepared as follows: $A \beta_{25-35}$ protein $(1 \mathrm{mg})$ was dissolved in $1 \mathrm{ml}$ sterile water $(1 \mathrm{mmol} / \mathrm{l})$. Subsequently, $1 \mathrm{mmol} / 1 \mathrm{~A} \beta_{25-35}$ was incubated at $37^{\circ} \mathrm{C}$ for $4-7$ days, and the aged $A \beta_{25-35}$ was used for further neurotoxicity experiments. In the present study, cultured PC12 cells were divided into treatment and control groups. In the control group, the cells were cultured in high-glucose DMEM with $10 \%$ FCS for 48 h. In the experimental groups, the cells were cultured in the same medium as the control group, but the medium was supplemented with aged $A \beta_{25-35}$ at various concentration (10, 50, 90, 180 and $360 \mu \mathrm{mol} / \mathrm{l}$ ). Subsequent experiments were performed in the control and treatment groups.

\section{Apoptotic assays}

MTT assay. 3-(4,5-Dimethylthiazol-2-yl)-2,5-diphenyltetrazolium bromide (MTT) reacts with succinate dehydrogenase in mitochondria and is reduced into water-insoluble blue-violet formazan crystals. Formazan is deposited in living rather than dead cells; therefore, formazan colorimetry may be used to evaluate cell viability. After reaching the logarithmic growth phase, $100 \mu 1 \mathrm{PC} 12$ cells at a concentration of $3 \times 10^{4}$ cells $/ \mathrm{ml}$ were seeded in a 96-well culture plate and incubated for $24 \mathrm{~h}$ at $37^{\circ} \mathrm{C}$ with $5 \% \mathrm{CO}_{2}$. After changing the medium $(100 \mu \mathrm{l})$, PC12 cells in both the control $(n=5)$ and experimental groups $(n=5)$ continued to be cultured for another $48 \mathrm{~h}$, followed by the addition of $20 \mu \mathrm{l} \mathrm{MTT}(5 \mathrm{mg} / \mathrm{ml})$. The cells were incubated with MTT for another $4 \mathrm{~h}$, then disrupted with $150 \mu 1$ dimethyl sulfoxide. After shaking for $10 \mathrm{~min}$, the absorbance (OD) values of the sample were read using a microplate reader (Bio-Rad Laboratories, Inc., Hercules, CA, USA) at a wavelength of $570 \mathrm{~nm}(\mathrm{n}>3)$.

4',6-Diamidino-2-phenylindole (DAPI) and terminal deoxynucleotidyl transferase dUTP nick-end labeling (TUNEL) staining. PC12 cells in the logarithmic growth phase $\left(1 \times 10^{5}\right.$ cells $\left./ \mathrm{ml}\right)$ were used for DAPI and TUNEL assays. The cells in the control and experimental groups were fixed with $4 \%$ paraformaldehyde $(\mathrm{pH} 7.4)$ at $4^{\circ} \mathrm{C}$ for $30 \mathrm{~min}$. After washing 3 times with $0.01 \mathrm{~mol} / 1$ phosphate-buffered saline (PBS), the cells were coverslipped with DAPI-glycerin (DAPI:65\% glycerol $=1: 1,000)$ and examined with a fluorescent microscope (BX61; Olympus, Tokyo, Japan). With DAPI staining, the cell nuclei and apoptotic bodies (condensed and fragmented nuclei) were visualized. TUNEL staining was also performed using a TUNEL assay kit (G3250; Promega, Madison, WI, USA). Cell collection and fixation were performed as described above. Subsequently, the cells were treated with $0.2 \%$ Triton X-100 to increase cell transparency. After rinsing with $0.01 \mathrm{~mol} / \mathrm{l} \mathrm{PBS}$ three times, TUNEL reaction solution was added, followed by incubation at $37^{\circ} \mathrm{C}$ for $60 \mathrm{~min}$. The reaction was then stopped with termination solution. The sections were coverslipped with DAPI-glycerin and examined with an epifluorescence micro-

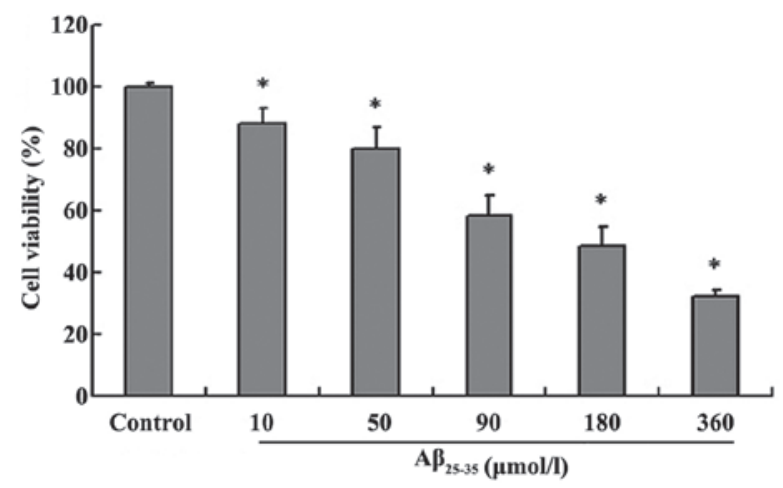

Figure 1. Viability of PC12 cells following $\beta$-amyloid $(\mathrm{A} \beta)_{25-35}$ treatment (MTT method). Values are presented as mean \pm standard deviation $(n=15)$. Following treatment with $\mathrm{A} \beta_{25-35}$, the viability of PC12 cells decreased in a dose-dependent manner compared with the control group. ${ }^{*} \mathrm{P}<0.05$ vs. control group. MTT, 3-(4,5-dimethylthiazol-2-yl)-2,5-diphenyltetrazolium bromide.

scope (BX61; Olympus) following excitation with rhodamine or ultraviolet (UV) light.

Cytoskeleton visualization with phalloidin staining and immunocytochemistry

Phalloidin staining. F-actin is the main component of microfilaments, and is capable of binding with phalloidin. Therefore, phalloidin may be used to stain microfilaments in the cell. Cells in the control and experimental groups were collected as described above and fixed in $4 \%$ paraformaldehyde for $30 \mathrm{~min}$. Subsequently, $0.2 \mu \mathrm{g} / \mathrm{ml}$ phalloidin (A12380; Invitrogen; Thermo Fisher Scientific; Carlsbad, CA, USA) was diluted with preparation solution $\left(0.1 \% \mathrm{NaN}_{3}, 3 \%\right.$ BSA, $0.3 \%$ Triton X-100 in 0.01 M PBS). After washing with $0.01 \mathrm{M} \mathrm{PBS}$, the cells were incubated with phalloidin solution overnight and coverslipped with DAPI-glycerin. The cells were examined under a fluorescence microscope following rhodamine or UV excitation.

Immunocytochemistry. The main component of microtubules is $\beta$-II-tubulin, which was used as a marker in the present study to visualize microtubules. The primary antibody used was rabbit anti- $\beta$-II-tubulin polyclonal antibody (1:100, AB151318; Abcam, Cambridge, MA, USA). The cells were incubated with the primary antibody at $4^{\circ} \mathrm{C}$ overnight. After washing with 0.01 M PBS 3 times, secondary antibody (Alexa Fluro 488 donkey anti-rabbit IgG, 1:500, A21206; Invitrogen; Thermo Fisher Scientific) was added and incubated at room temperature for $3 \mathrm{~h}$. The cells were coverslipped with DAPI-glycerin, observed and photographed with a fluorescence microscope.

Measurements and statistical tests. The MTT assay was used to evaluate the viability of PC12 cells as follows: Cell survival rate $(\%)=\left(\mathrm{OD}_{570}\right.$ in the experimental group - $\mathrm{OD}_{570}$ in the blank group $) /\left(\mathrm{OD}_{570}\right.$ in the control group - $\mathrm{OD}_{570}$ in the blank group) $\mathrm{x} 100 \%$. The remaining cultured cells were considered as non-viable, including necrotic and apoptotic cells. Using the cell survival rate, the ratio of non-viable cells was calculated using the formula: 1 - cell survival rate (\%). ImageJ 1.48 software was used to quantify the apoptotic cells and disintegrated cytoskeleton as follows: Apoptotic rate (DAPI or TUNEL staining) $=$ (apoptotic cells/total cells) $\times 100 \%$. Cytoskeleton disintegration $=($ number of cells with disintegrated cytoskeleton/total cell number) $\mathrm{x} 100 \%$. 

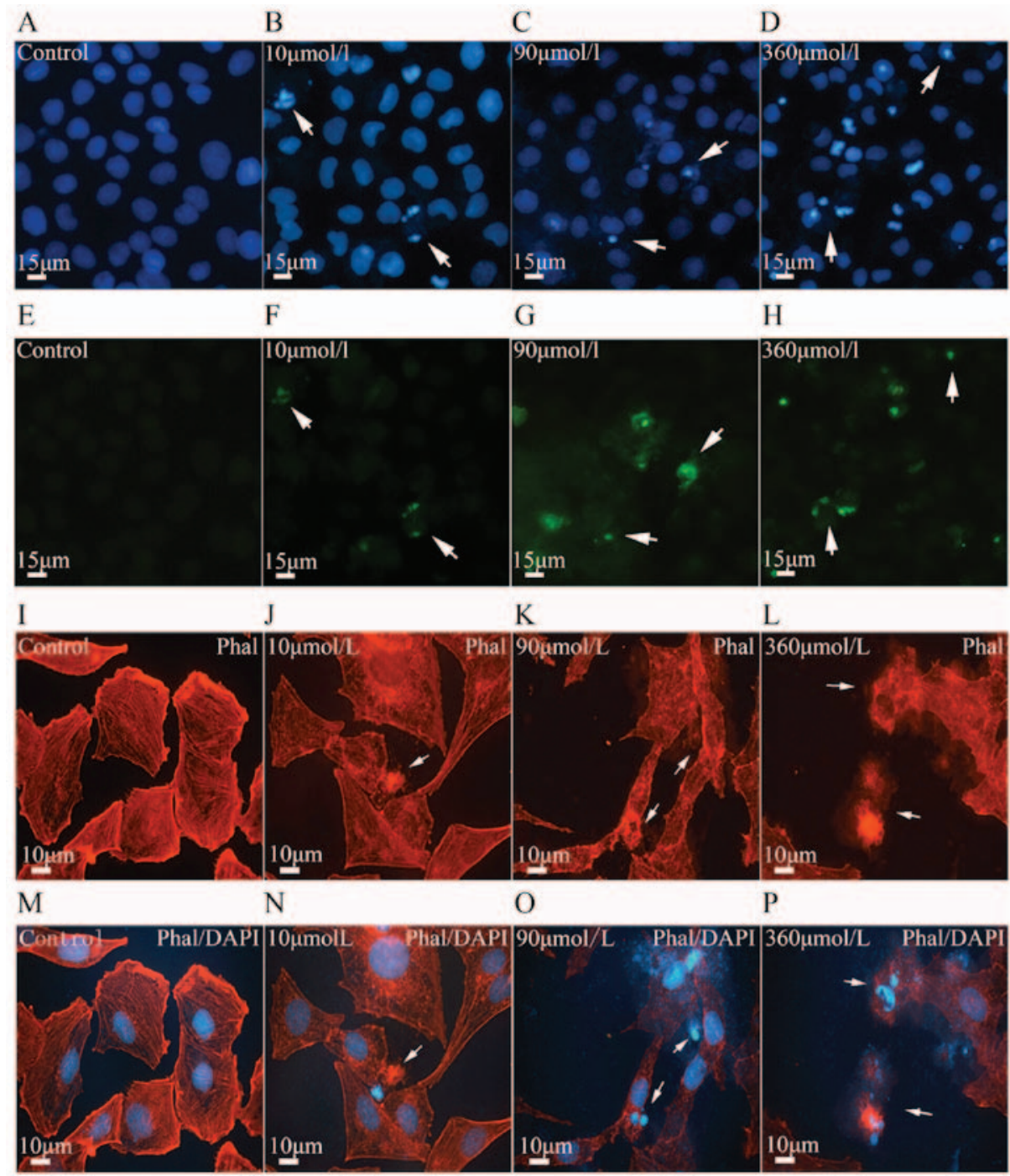

Figure 2. Cell apoptosis and microfilament alterations following $\beta$-amyloid $(\mathrm{A} \beta)_{25-35}$ treatment (phalloidin staining and DAPI counterstaining). (A-D) Nuclear condensation and apoptotic bodies (arrows) were visualized with DAPI staining (blue) in the control and treatment groups. (E-H) Cell apoptosis determined with the TUNEL assay. A $\beta_{25-35}$ induced PC12 cell apoptosis (green, arrows) in a dose-dependent manner. (I-P) A $\beta_{25-35}$ neurotoxicity and microfilament alterations (phalloidin staining and DAPI counterstaining). Following $\mathrm{A} \beta_{25-35}$ treatment, the microfilaments (red) in PC12 cells appeared to disintegrate (arrows). The disintegrated microfilaments ( $\mathrm{J}$ and $\mathrm{L}$, arrows) were often observed in apoptotic cells with condensed nuclei or apoptotic bodies (N and $\mathrm{P}$, arrows). With increasing $A \beta_{25-35}$ dose, the number of cells with disintegrated microfilaments gradually increased. Scale bars, $15 \mu \mathrm{m}$ in (A-H) and $10 \mu \mathrm{m}$ in (I-P). TUNEL, terminal deoxynucleotidyl transferase dUTP nick-end labeling; DAPI, 4',6-diamidino-2-phenylindole; Phal, phalloidin.

In order to exclude the interference of necrosis, we also estimated the proportional contribution of apoptosis to the viable reduction according to the formula: Neurapoptosis/non-viable cells $=$ apoptotic rate $/(1$ - cell survival rate) $(\%)$.

Statistical analysis. All data were recorded as mean \pm standard deviation. Using SPSS 11.5 statistical software (SPSS, Inc., Chicago, IL, USA), comparisons of the abovementioned parameters were performed between the experimental and control groups with one-way analysis of variance. $\mathrm{P}<0.05$ was considered to indicate statistically significant differences, and $\mathrm{P}<0.01$ was considered as highly statistically significant.

\section{Results}

$A \beta_{25-35}$ neurotoxicity and neuroapoptosis in PC12 cells. The MTT assay was used to detect cell viability following exposure to $A \beta_{25-35}$ toxicity (9). The results revealed that $A \beta_{25-35}$ decreased cell viability in a dose-dependent manner compared with the control group. Cell survival was gradually reduced with increasing concentrations of $\mathrm{A} \beta_{25-35}(10,50,90,180$ and $360 \mu \mathrm{mol} / 1 ;$ P $<0.05$, Fig. 1).

In order to determine whether the reduction in cell survival was caused by cell apoptosis, TUNEL assay with DAPI counterstaining was performed. DAPI stains cell nuclei with blue color. The PC12 cells in the control group appeared to grow well, with uniform brightness, and their nuclei had a smooth outline with homogeneous chromatin distribution. However, the cells in the experimental group displayed pyknotic nuclear chromatin, which was often marginated along the nuclear edge, conferring an appearance of half moon-like nuclei, with occasional formation of typical apoptotic bodies (Fig. 2A-D). With increasing $\mathrm{A} \beta_{25-35}$ dose, the number of apoptotic cells gradually increased in a dose-dependent manner (P<0.05; Fig. 3A). TUNEL assay confirmed the results of DAPI staining. Apoptotic cells were hardly found in the control group; however, following $A \beta_{25-35}$ 
A

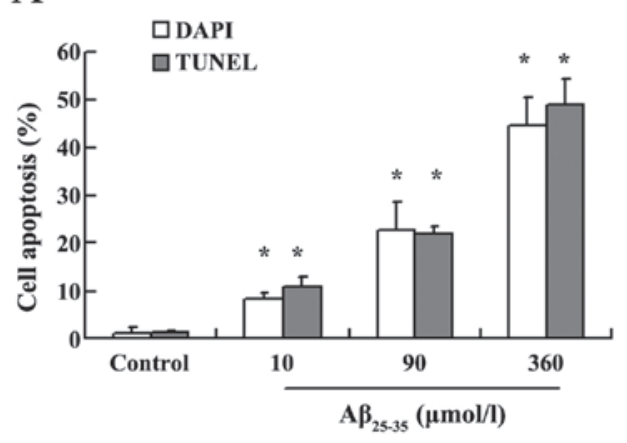

$\mathrm{B}$

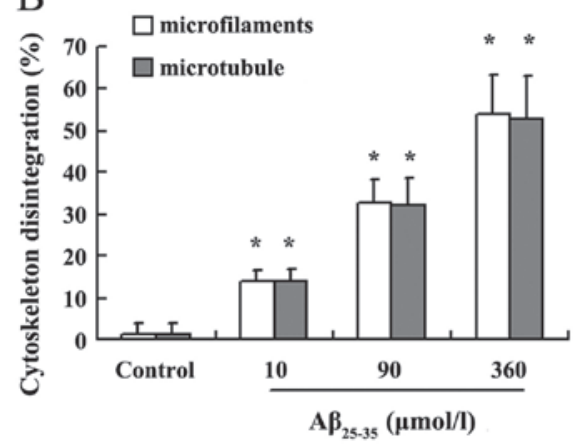

Figure 3. Histograms of cell apoptosis and cytoskeletal disintegration among various groups (mean \pm standard deviation) (n=5). (A) The apoptotic cells were visualized with DAPI and TUNEL staining, and the apoptotic rate was measured and calculated with ImageJ software. Compared with the control group, $\mathrm{A} \beta_{25-35}$ induced cell apoptosis dose-dependently. "P $<0.05$ vs. control group. (B) The number of cells with disassembled microfilaments and microtubules was also compared between the treatment and control groups. "P<0.05 vs. control. TUNEL, terminal deoxynucleotidyl transferase dUTP nick-end labeling; DAPI, 4',6-diamidino-2-phenylindole.

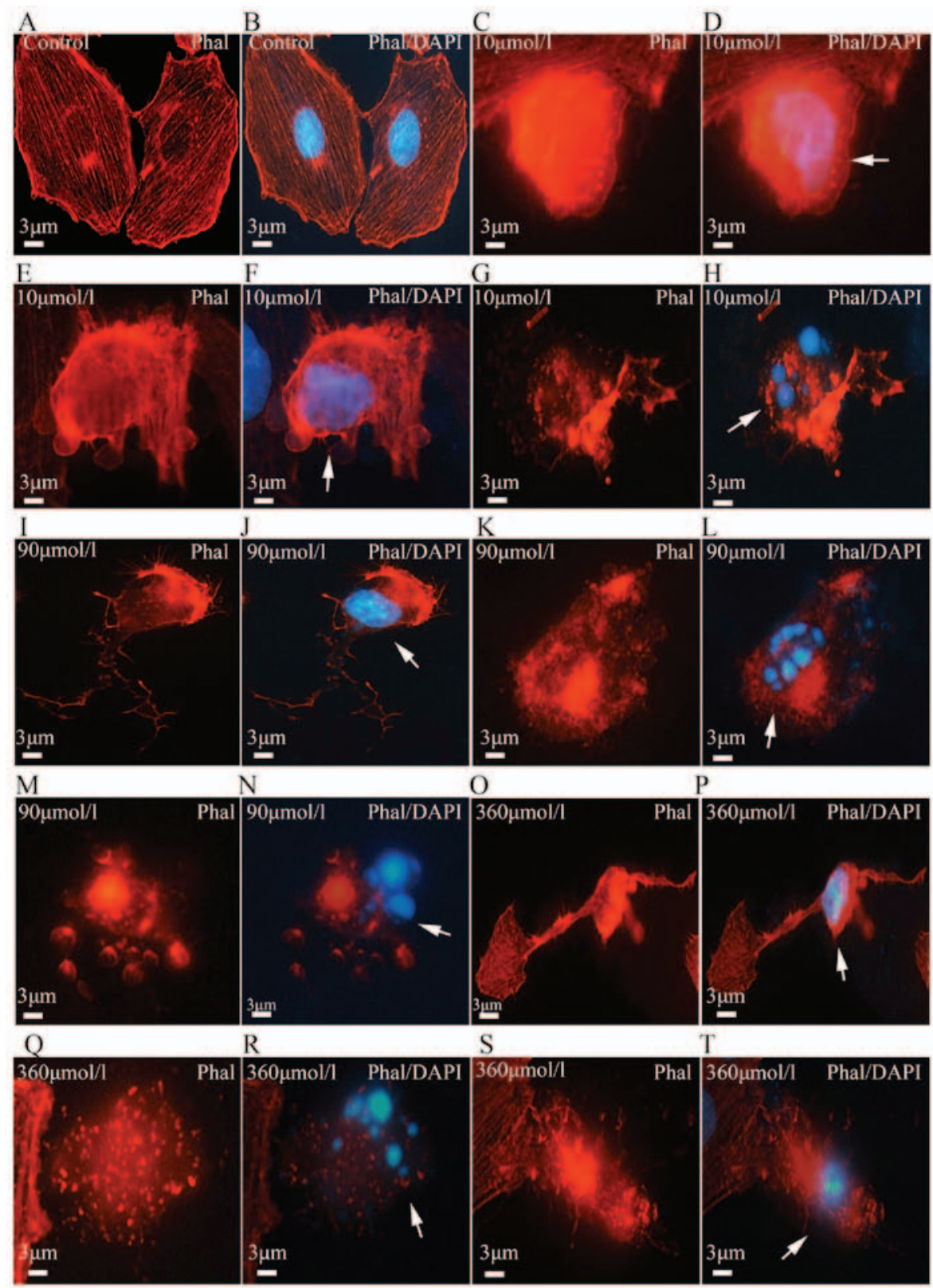

Figure 4. Neurotoxicity and microfilament alterations induced by $\beta$-amyloid $(\mathrm{A} \beta)_{25-35}$ under high magnification (phalloidin staining and DAPI counterstaining). (A and B) In the control group, numerous microfilaments were found in the cytoplasm. (C-T) However, in the treatment groups, the microfilaments collapsed and disintegrated in a dose-dependent manner. ( $\mathrm{C}$ and $\mathrm{T}$, arrows) The cells with disintegrated microfilaments were usually apoptotic cells with condensed and fragmented nuclei. Scale bar, $3 \mu \mathrm{m}$. Phal, phalloidin staining; DAPI, 4',6-diamidino-2-phenylindole. 

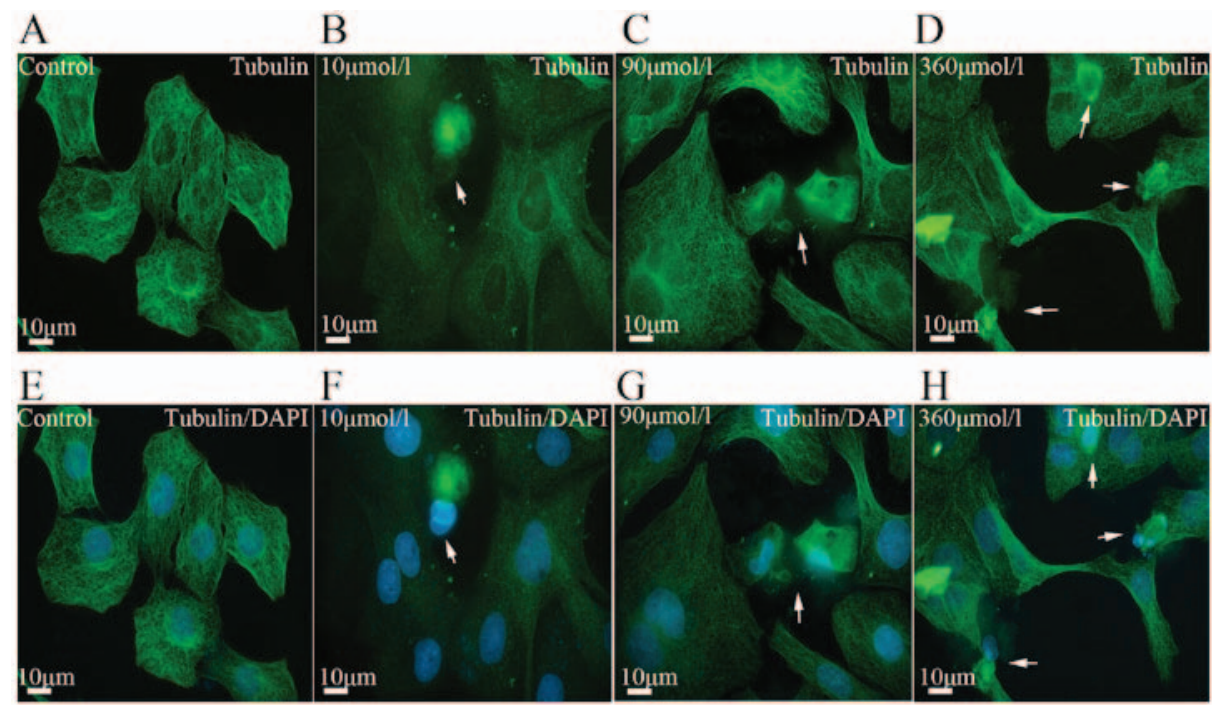

Figure 5. (A-H) Neurotoxicity and microtubule disintegration induced by $\beta$-amyloid $(\mathrm{A} \beta)_{25-35}$ ( $\beta$-II-tubulin immunolabeling and DAPI counterstaining). Microtubules were labeled with $\beta$-II-tubulin immunolabeling (green), and cell nuclei were counterstained with DAPI (blue). (A and H) Following A $\beta_{25-35}$ treatment, the microtubules in PC12 cells disintegrated (arrows) in a dose-dependent manner. Scale bar, $10 \mu \mathrm{m}$. DAPI, 4',6-diamidino-2-phenylindole.

treatment, the number of apoptotic cells identified with TUNEL staining increased in a dose-dependent manner $(\mathrm{P}<0.05$; Fig. 3A). The apoptotic cells observed with DAPI staining and the TUNEL-positive cells usually overlapped (Fig. 2A-H). In the present study, neurapoptosis/non-viable cells were calculated under various $\mathrm{A} \beta$ concentrations; at $\mathrm{A} \beta_{25-35}$ concentrations of 10 , $50,90,180$ and $360 \mu \mathrm{mol} / 1$, neuroapoptosis/non-viable cells was $95.41,87.18,83.61,82.87$ and $84.51 \%$, respectively, suggesting neuroapoptosis was the main cause of cell death.

A $\beta_{25-35}$ neurotoxicity and cytoskeletal alterations in PC12 cells. The cytoskeleton is an important component of eukaryotic cells, and it plays a key role in the maintenance of cell shape, intracellular substance transportation and cell amoeba-like movement. Recent studies reported that there is a close association between cytoskeletal abnormalities and cell apoptosis. It was previously demonstrated that, during cell division, suppressed microtubule assembly is followed by protein kinase activation and induction of cell apoptosis (10). In yeast and certain types of animal cells, such as HL-60 cells, depolymerization of microfilaments may be induced in apoptotic cells (11). In the present study, major changes were observed in the cytoskeleton following $A \beta_{25-35}$ treatment. The cells in the control group contained numerous microfilaments with intensive fluorescence and a clear outline. Microfilaments of varying lengths exhibited a rod-like appearance and were parallelly arranged. Following $A \beta_{25-35}$ treatment, the microfilaments in the apoptotic cells appeared vague and started to disintegrate (Figs. 2I-P and 4). Statistical analysis revealed that the microfilament disintegration rate increased in $\mathrm{A} \beta_{25-35}$ treatment groups in a dose-dependent manner $(\mathrm{P}<0.05$; Fig. 3B). Furthermore, a neurotoxic effect of $\mathrm{A} \beta_{25-35}$ on microtubules was also observed. In the control group, the fibrous microtubules formed a web structure around the nucleus. In the experimental groups, the microtubules started to disintegrate and even aggregate in dense lumps (Fig. 5). These pathological alterations were often observed in apoptotic cells (Fig. 6E-T). Statistical analysis revealed that $\mathrm{A} \beta_{25-35}$ induced microtubule disintegration in a dose-dependent manner compared with the control group ( $\mathrm{P}<0.05$; Fig. 3B).

\section{Discussion}

$\mathrm{A} \beta_{25-35}$ induces neuroapoptosis in $\mathrm{PC} 12$ cells. Apoptosis plays a crucial role during cell differentiation, organ development and pathogenesis $(12,13)$; it is also physiologically important for neural pathfinding and synaptogenesis during brain development. Neuroapoptosis may also occur during cell aging, neuronal injury and neural degenerative diseases. $\mathrm{AD}$ is one of the most common neurodegenerative diseases, and the mechanism underlying its pathogenesis is extremely complex. Scientists believe that $\mathrm{A} \beta$ is a key factor in the development of $\mathrm{AD} . \mathrm{A} \beta$ is cleaved from amyloid precursor protein by $\beta$ - or $\gamma$-hydrolase. $A \beta$ consists of 39-43 amino acid residues and it has three types, namely $\mathrm{A} \beta_{25-35}, \mathrm{~A} \beta_{1-42}$ and $\mathrm{A} \beta_{1-40}$, of which $\mathrm{A} \beta_{25-35}$ is considered to be the most toxic. In the present study, the neurotoxic effect of $A \beta_{25-35}$ on PC12 cells was assessed. As Loo et al (14) and Kim et al (15) previously reported, $A \beta$ induces neuronal apoptosis and necrosis. The present study demonstrated that $A \beta_{25-35}$ reduced cell viability, as determined by the MTT assay. In addition, $A \beta_{25-35}$ also caused PC12 cell apoptosis in a dose-dependent manner. It was also determined that apoptosis was the main contributor to cell death in non-viable cells, indicating that neuropoptosis is a key factor in $\mathrm{AD}$ pathogenesis. The mechanism underlying $\mathrm{A} \beta$ neurotoxicity is complex, and likely involves cell oxidative stress and intracellular calcium deregulation. Deposition of $\mathrm{A} \beta$ triggers the oxidative stress response in cells, and calcium balance is disturbed. These events then trigger cell apoptosis through the endoplasmic reticulum and death receptor pathways $(7,16)$. In the present study, $A \beta$ clearly induced neuroapoptosis; however, the findings require confirmation by further studies.

$\mathrm{A} \beta_{25-35}$ induced disintegration of the cytoskeleton. Microfilaments and microtubules are crucial for cell functions. If the cytoskeleton is disintegrated, inevitable pathological alterations will occur. Previous studies reported that the cytoskeletal malformations during the pathogenesis of Huntington's chorea, Parkinson's disease and AD (17). As a key risk factor of AD pathogenesis, $A \beta$ induces neuronal cytoskeleton abnormalities $(18,19)$. In the present study, following $A \beta_{25-35}$ treatment, the cytoskeleton 

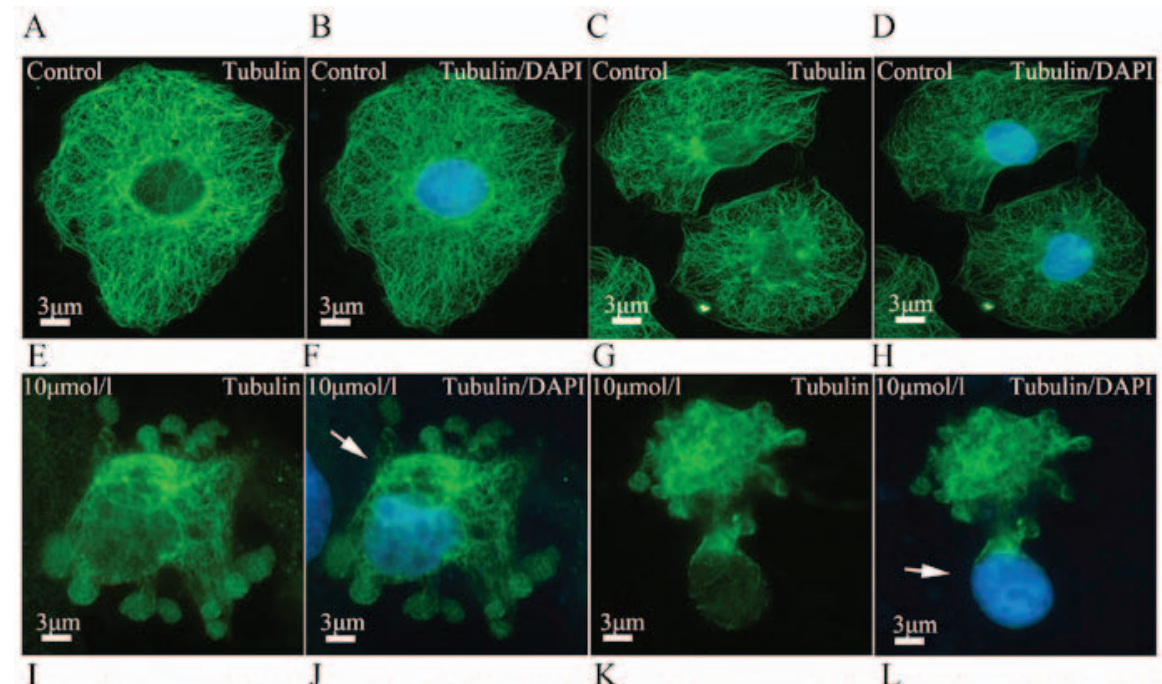

G

$\mathrm{H}$
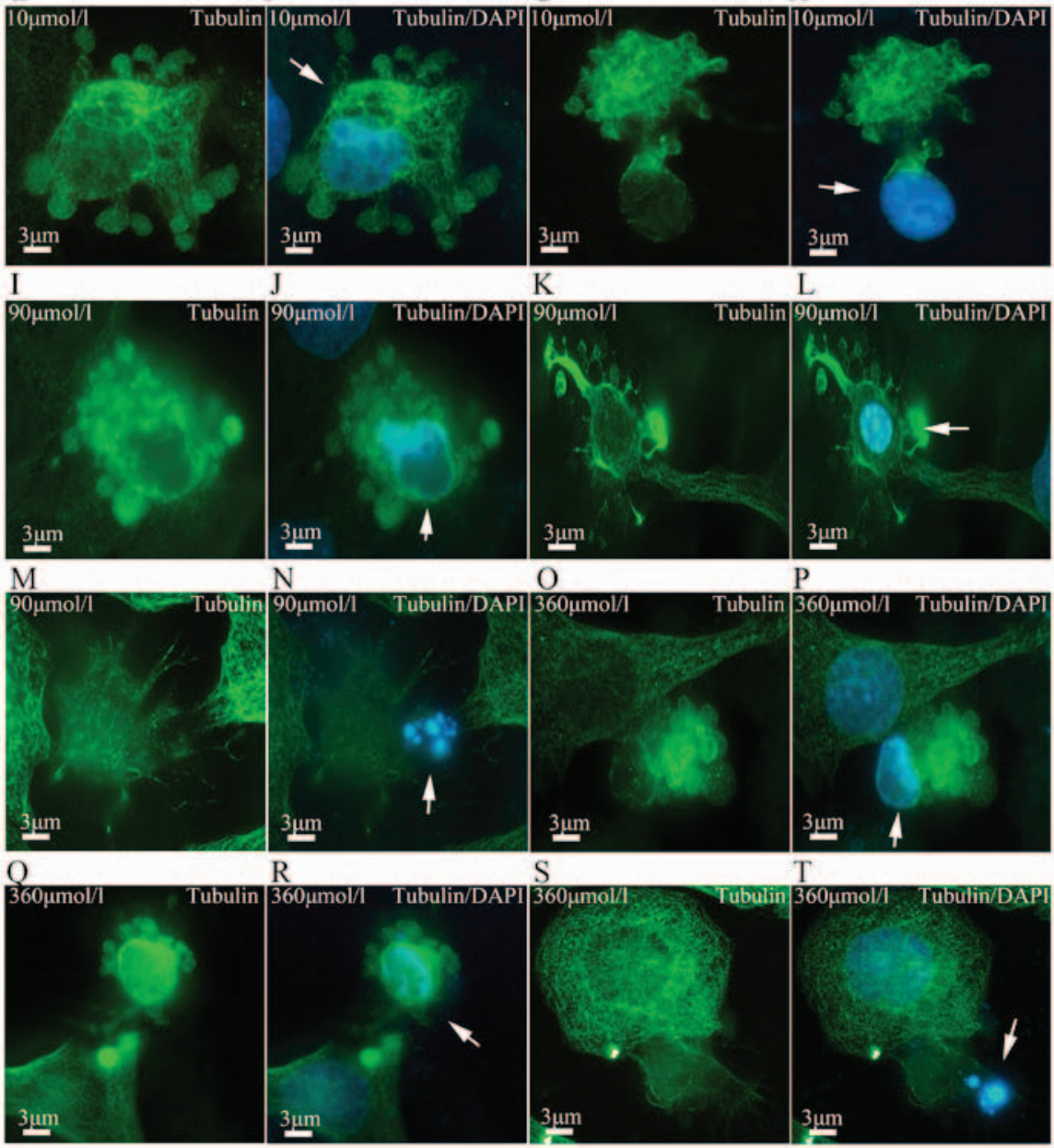

Figure 6. Neurotoxicity and microtubule alterations induced by $\beta$-amyloid $(\mathrm{A} \beta)_{25-35}$ in cells under high magnification ( $\beta$-II-tubulin immunolabeling and DAPI counterstaining). (A-D) The microtubules were arranged in a web-like formation around the nucleus in the control group. (E-T) In the A $\beta_{25-35}$ treatment groups, collapsed and disintegrated microtubules were observed in apoptotic cells with fragmented nuclei (arrows). Scale bar, $3 \mu$ m. DAPI, 4',6-diamidino-2-phenylindole.

collapsed and disintegrated in a dose-dependent manner. Cytoskeletal disintegration was often observed in apoptotic cells. The changes in the treatment groups were similar to those reported in the brain of an $\mathrm{AD}$ patient, exhibiting nerve inflammation and destruction of the cytoskeleton caused by $\mathrm{A} \beta$ neurotoxicity and Tau protein hyperphosphorylation (20). It is known that $\mathrm{A} \beta$ may trigger certain signaling pathways and cause rearrangement of the microfilament and microtubule network, leading to neuronal function disorders $(21,22)$. The microtubule-associated proteins regulate the arrangement of the microtubules, and the Tau protein promotes microtubule assembly; therefore, $A \beta$ neurotoxicity by cytoskeletal disintegration is probably mediated by the activity of cytoskeleton-related proteins; however, the detailed mechanism requires further investigation.

Cytoskeletal disintegration is an important pathological event in AD. According to the AD cell model constructed by
Ostrovskaya et al (23), the neurotoxicity of $\mathrm{A} \beta_{25-35}$ was investigated in PC12 cells in an attempt to elucidate the association between $\mathrm{A} \beta$ neurotoxicity and $\mathrm{AD}$ pathogenesis. The results demonstrated that $\mathrm{A} \beta_{25-35}$ induced PC12 cell apoptosis and cytoskeletal disintegration. Previous studies also demonstrated that cell apoptosis is accompanied by cytoskeletal destruction (24). In the present study, $A \beta_{25-35}$ induced cell apoptosis and cytoskeletal disintegration, which is likely the main pathological basis of neurofibrillary tangle formation in AD. According to the amyloid cascade hypothesis, $A \beta$ may promote abnormal phosphorylation of the Tau protein (25), cell apoptosis and cytoskeletal disintegration. The present study suggests that $A \beta_{25-35}$ induces not only cell apoptosis, but also cytoskeletal disintegration.

In conclusion, $\mathrm{A} \beta_{25-35}$ decreased the viability of PC12 cells and induced cell apoptosis in a dose-dependent manner. The cytoskeleton is also very sensitive to the neurotoxic effects of 
$\mathrm{A} \beta_{25-35}$, leading to cytoskeletal disintegration. As indicated by the present study, this $A \beta$-induced cytoskeletal disintegration is likely an important event in the pathological base of neurofibrillary tangle formation during AD pathogenesis. These findings will hopefully provide a new approach to the prevention and treatment of AD.

\section{Acknowledgements}

Not applicable.

\section{Funding}

The present study was supported by the National Natural Science Foundation of China (grant no. U1204311), Henan University Youth Training Foundation (grant nos. 0000A40356 and 0000A40475), Henan Postdoctoral Foundation (grant no. 2015051) and Henan Province Research Program of Basic and Advanced Technology (grant no. 172102310001).

\section{Availability of data and materials}

All data generated or analyzed during this study are included in this published article.

\section{Authors' contributions}

LW, JC, ZS and JinD designed the study, and performed the analyses. WF and HL analyzed data. JinD and JieD were involved in the conception of the study and wrote the manuscript. The final version of the manuscript has been read and approved by all authors.

\section{Ethics approval and consent to participate}

The protocol was approved by the Committee of Medical Ethics and Welfare for Experimental Animals, Henan University School of Medicine (HUSOM:2015-87).

\section{Consent for publication}

Not applicable.

\section{Competing interests}

The authors declare that they have no competing interests.

\section{References}

1. Henley DB, Dowsett SA, Chen YF, Liu-Seifert H, Grill JD, Doody RS, Aisen P, Raman R, Miller DS, Hake AM, et al: Alzheimer's disease progression by geographical region in a clinical trial setting. Alzheimers Res Ther 7: 43, 2015.

2. Dong MJ, Peng B, Lin XT, Zhao J, Zhou YR and Wang RH: The prevalence of dementia in the People's Republic of China: a systematic analysis of 1980-2004 studies. Age Ageing 36: 619-624, 2007

3. Barage SH and Sonawane KD: Amyloid cascade hypothesis: pathogenesis and therapeutic strategies in Alzheimer's disease. Neuropeptides 52: 1-18, 2015.

4. Sadigh-Eteghad S, Sabermarouf B, Majdi A, Talebi M, Farhoudi $\mathrm{M}$ and Mahmoudi J: Amyloid-beta: a crucial factor in Alzheimer's disease. Med Princ Pract 24: 1-10, 2015.
5. Shen ZY, Xu LY, Li EM, Li JT, Chen MH, Shen J and Zeng Y: Ezrin, actin and cytoskeleton in apoptosis of esophageal epithelial cells induced by arsenic trioxide. Int J Mol Med 12: 341-347, 2003.

6. Rudrabhatla P: Regulation of neuronal cytoskeletal protein phosphorylation in neurodegenerative diseases. J Alzheimers Dis 41: 671-684, 2014.

7. Kaminsky YG, Marlatt MW, Smith MA and Kosenko EA Subcellular and metabolic examination of amyloid-beta peptides in Alzheimer disease pathogenesis: evidence for Abeta(25-35). Exp Neurol 221: 26-37, 2010.

8. Pike CJ, Walencewicz AJ, Glabe CG and Cotman CW: In vitro aging of beta-amyloid protein causes peptide aggregation and neurotoxicity. Brain Res 563: 311-314, 1991.

9. Hatok J, Babusikova E, Matakova T, Mistuna D, Dobrota D and Racay P: In vitro assays for the evaluation of drug resistance in tumor cells. Clin Exp Med 9: 1-7, 2009.

10. Ndozangue-Touriguine O, Hamelin J and Bréard J: Cytoskeleton and apoptosis. Biochem Pharmacol 76: 11-18, 2008.

11. Gourlay CW, Carpp LN, Timpson P, Winder SJ and Ayscough KR: A role for the actin cytoskeleton in cell death and aging in yeast. $\mathrm{J}$ Cell Biol 164: 803-809, 2004.

12. Dekkers MP, Nikoletopoulou V and Barde YA: Cell biology in neuroscience: death of developing neurons: new insights and implications for connectivity. J Cell Biol 203: 385-393, 2013.

13. Chen A, Xiong LJ, Tong Y and Mao M: The neuroprotective roles of BDNF in hypoxic ischemic brain injury. Biomed Rep 1: 167-176, 2013.

14. Loo DT, Copani A, Pike CJ, Whittemore ER, Walencewicz AJ and Cotman CW: Apoptosis is induced by beta-amyloid in cultured central nervous system neurons. Proc Natl Acad Sci USA 90: 7951-7955, 1993.

15. Kim IK, Lee KJ, Rhee S, Seo SB and Pak JH: Protective effects of peroxiredoxin 6 overexpression on amyloid $\beta$-induced apoptosis in PC12 cells. Free Radic Res 10: 836-846, 2013.

16. Green DR and Llambi F: Cell death signaling. Cold Spring Harb Perspect Biol 7: 7, 2015

17. Leadsham JE, Kotiadis VN, Tarrant DJ and Gourlay CW: Apoptosis and the yeast actin cytoskeleton. Cell Death Differ 17: 754-762, 2010.

18. Hardy J: Has the amyloid cascade hypothesis for Alzheimer's disease been proved? Curr Alzheimer Res 3: 71-73, 2006.

19. Henriques AG, Vieira SI, da Cruz E Silva EF and da Cruz E Silva OA: Abeta promotes Alzheimer's disease-like cytoskeleton abnormalities with consequences to APP processing in neurons. J Neurochem 113: 761-771, 2010.

20. Jin M, Shepardson N, Yang T, Chen G, Walsh D and Selkoe DJ: Soluble amyloid beta-protein dimers isolated from Alzheimer cortex directly induce Tau hyperphosphorylation and neuritic degeneration. Proc Natl Acad Sci USA 108: 5819-5824, 2011.

21. Sohn PD, Tracy TE, Son HI, Zhou Y, Leite RE, Miller BL, Seeley WW, Grinberg LT and Gan L: Acetylated Tau destabilizes the cytoskeleton in the axon initial segment and is mislocalized to the somatodendritic compartment. Mol Neurodegener 11: 47, 2016.

22. Deng Y, Wei J, Cheng J, Zhong P, Xiong Z, Liu A, Lin L, Chen S and Yan Z: Partial amelioration of synaptic and cognitive deficits by inhibiting cofilin dephosphorylation in an animal model of Alzheimer's disease. J Alzheimers Dis 53: 1419-1432, 2016.

23. Ostrovskaya RU, Vakhitova YV, Kuzmina US, Salimgareeva MK, Zainullina LF, Gudasheva TA, Vakhitov VA and Seredenin SB: Neuroprotective effect of novel cognitive enhancer noopept on AD-related cellular model involves the attenuation of apoptosis and Tau hyperphosphorylation. J Biomed Sci 21: 74, 2014.

24. Thomas SG, Huang S, Li S, Staiger CJ and Franklin-Tong VE: Actin depolymerization is sufficient to induce programmed cell death in self-incompatible pollen. J Cell Biol 174: 221-229, 2006.

25. Xu J, Zhang R, Zuo P, Yang N, Ji C, Liu W, Wang Y, Wang H, Wu A, Yue Y, et al: Aggravation effect of isoflurane on $\mathrm{A} \beta(25-35)$-induced apoptosis and Tau hyperphosphorylation in PC1 2 cells. Cell Mol Neurobiol 32: 1343-1351, 2012.

This work is licensed under a Creative Commons Attribution-NonCommercial-NoDerivatives 4.0 International (CC BY-NC-ND 4.0) License. 